\title{
Representing Kolkata : A Study of 'Gaze' Construction in Amit Chaudhuri's Calcutta: Two Years in the City and Bishwanath Ghosh's Longing Belonging: An Outsider at Home in Calcutta
}

\author{
Saurabh Sarmadhikari \\ Assistant Professor, Department of English, Gangarampur College, Dakshin Dinajpur, West \\ Bengal. ORCID: oooo-ooo2-8577-4878. Email: saurabhsarmadhikari@gmail.com
}

\begin{abstract}
Indian travel writings in English exclusively on Kolkata have been rare even though tourist guidebooks such as the Lonely Planet have dedicated sections on the city. In such a scenario, Amit Chaudhuri's Calcutta: Two Years in the City (2016) and Bishwanath Ghosh's Longing Belonging: An Outsider at Home in Calcutta (2014) stand out as exceptions. Both these narratives, written by probashi (expatriate) Bengalis, represent Kolkata though a bifocal lens. On the one hand, their travels are a journey towards rediscovering their Bengali roots and on the other, their representation/construction of the city of Kolkata is as hard-boiled as any seasoned traveller. The contention of this paper is that both Chaudhuri and Ghosh foreground certain selected/predetermined signifiers that are common to Kolkata for the purpose of their representation which are instrumental in constructing the 'gaze' of their readers towards the city. This process of 'gaze' construction is studied by applying John Urry and Jonas Larsen's conceptualization of the 'tourist gaze'. Borrowing the Foucauldian concept of 'gaze', Urry and Larsen state that 'gazing' is a discursive practice that is both constituted by the filters of the gazer's cultural moorings as well as the institutionalized mechanisms of the travel/tourism industry which rely significantly on the deployment of signs and signifiers to construct the 'gaze' of the travellers and the tourists towards a tourist destination. The present paper seeks to analyze how both Chaudhuri and Ghosh use 'selective' signifiers of the city of Kolkata to construct the 'gaze' of their readers towards the city in their representation.
\end{abstract}

Keywords: representation, gaze, construction, Kolkata, travel narratives

\section{Introduction}

Though Calcutta has been one of India's most significant cities since its founding in the seventeenth century and though it has been the capital of British India until 1911, travel writings in English dealing exclusively on the city of Calcutta have been few and far between. There have been diverse and exhaustive socio-cultural studies on the city such as H.E. Busteed's Echoes from Old Calcutta (1888), P. Thankappan Nair's three-volume study on Calcutta-(Calcutta in the $17^{\text {th }}$ Century (1984), Calcutta in the $18^{\text {th }}$ Century (1985) and Calcutta in the $19^{\text {th }}$ Century (1989), or Sukanta Chaudhuri's edited volume Calcutta: The Living City (1990), but it has not been the case with travel writings on the city. Travel writings on Calcutta such as Days and Nights in Calcutta (1986) by Clark Blaise and Bharati Mukherjee, Abdul's Taxi to Kalighat (2000) by Joe Roberts or the recently published The Epic City: The World on the Streets of Calcutta (2017) by Kushanava Choudhury do exist but their focus is limited to particular aspects of the city. Similar in vein are

(C) AesthetixMS 2020. This Open Access article is published under a Creative Commons Attribution Non-Commercial 4.o International License (http://creativecommons.org/licenses/by-nc/4.o/), which permits non-commercial re-use, distribution, and reproduction in any medium, provided the original work is properly cited. For citation use the DOI. For commercial re-use, please contact editor@rupkatha.com. 
the representations of Calcutta in select chapters on Indian travel writings in English such as the Chapter 'After the Battle' in V. S. Naipaul's India: A Million Mutinies Now (1990) or the subsections 'Conversations in Kolkata' and 'Godmen and Ghosts' in the Chapter 'Cities of the Plain' of Out of God's Oven: Travels in a Fractured Land (2002) by Dom Moraes and Sarayu Srivatsa. One might also mention the fleeting images of the city in such narratives as in the extract 'Refugees' from James Cameron's An Indian Summer (included in the Dom Moraes edited The Penguin Book of Indian Journeys (2001)). But exception must be made about Calcutta (1971) by Geoffrey Moorhouse which might be considered as one of the first full-length representations of the city of Calcutta as far as travel narratives in English are concerned. The narratives under consideration in this paper, Amit Chaudhuri's Calcutta: Two Years in the City (2016) and Bishwanath Ghosh's Longing Belonging: An Outsider at Home in Calcutta (2014) follow the same tradition of representation of Calcutta as laid down by Moorhouse.

But, representation, as such, is not merely an innocuous exercise involving description or depiction of the city space/scape of Calcutta. Rather, it is a discursive exercise beset with questions of inclusion and exclusion, foregrounding and back-grounding of issues and events. As far as this paper is concerned, such an interpretation of representation is based on Stuart Hall's theorizing of representation in his Representation: Cultural Representations and Signifying Practices ((1997) that lays emphasis on representation as the basis of meaning production in contemporary society and culture. Hall also points out that at a basic level it is language that forms the primary building block of any representation because "language operates as a representational system" (Hall, 1997, p.1) in any culture. Probing further still, Hall states that the signs and symbols that constitute language are fundamentally responsible for any sort of representation to take place. In other words, it is in the manner of deployment of signs and symbols in any narrative form that the discursive inclinations of the language used become apparent. And travel narratives are no exception. Seen from this perspective then, travel narratives cease to function as mere descriptions of travel depicting unknown/unencountered peoples and places and come across as discursive and value-laden statements determined by the narrator's subjective positioning in any particular socio-cultural axis.

This discursive deployment of signs again forms the basis of the construction of 'gaze' of tourists/travellers as well as the readers of travel narratives that the present paper seeks to analyze. It was John Urry and Jonas Larsen who adapted Foucault's idea of the 'medical gaze', propounded in his The Clinic (1976), and introduced the concept of the 'tourist gaze' in their The Tourist Gaze 3.o (2011). Urry and Larsen contend that 'gazing' is not merely 'looking' or 'seeing', but a rather complex exercise determined by a range of varied factors which are discursive in nature: "People gaze upon the world through a particular filter of ideas, desires and expectations, framed by social class, gender, nationality, age and education. Gazing is a performance that orders, shapes and classifies, rather than reflects the world." (Urry \& Larsen, 2011, p.2) But again, this 'gazing' is not only conditioned by personal experiences and individual psychologies but also by the visual and representational discourses employed by the tourism industry. Urry and Larsen explore this dual facet of the 'tourist gaze' as they say:

The 'tourist gaze' is not a matter of individual psychology but of socially patterned and learnt 'ways of seeing'. It is a vision constructed through mobile images and representational technologies. Like the medical gaze, the power of the visual gaze within modern tourism is tied into, and enabled by, various technologies, including camcorders, film, TV, cameras and digital images. (Urry \& Larsen, 2011, p.2). 
Later on they go on to enumerate the varied professionals who are involved in 'constructing' this vision and the relationship that is produced/systematized between the gazer (the tourist) and the gazee (the tourist object):

These relations are discursively organised by many professionals: photographers, writers of travel books, blogs and guides, local councils, experts in the 'heritage industry', travel agents, hotel owners, designers, tour operators, TV travel programmes, tourism development officers, architects, planners, tourism academics and so on. (Urry \& Larsen, 2011, p.18)

As far as this paper is concerned, it attempts to analyze the strategies that Amit Chaudhuri and Bishwanath Ghosh adopt to represent Calcutta in their narratives as they construct the 'gaze' of their readers towards selected specificities of the city. This is done by focusing on two particular aspects of Calcutta that Chaudhuri and Ghosh highlight: (i) Spaces and (ii) Festivals. The spatial zones are: (a) Park Street and (b) North Calcutta and three major festivals being (a) Christmas, (b) New Year's Eve/ New Year Day and (c) Durga Puja.

\section{Spaces}

\section{Park Street}

In both Amit Chaudhuri's Calcutta: Two Years in the City (2016) and Bishwanath Ghosh's Longing Belonging: An Outsider at Home in Calcutta (2014) one of the most important signifiers that construct the city of Calcutta for the readers is Park Street and the areas adjoining it, especially Free School Street. Chaudhuri, as he constructs Park Street for his readers, foregrounds certain specific aspects of the area: (1) the cartographic location of Park Street; (2) the co-existence of pavement dwellers (along with their business establishments), the beggars, the pimps and the affluent middle-class eateries and shopping establishments that flank Park Street; and (3) detailed description of the landmark eateries and shopping establishments in Park Street.

Chaudhuri earmarks Park Street as one of the city's nerve centres and he suggests that 'Downtown' might be an appropriate description of the area. He goes on to map the area for his readers: "You have Free School Street on one end, Middleton Row, narrower and shorter, on the opposite side, and, at a right angle to these two, Park Street, this long road finally opening out on to the chaos of Park Circus, and, nearer this end, to the once-imperial artery, Chowringhee." (Chaudhuri, 2016, ch.2). This stretch of the Park Street is then contrasted with Oxford Street in London and the Champs-Élyseés in Paris and extolled for its incomparable level of energy.

The next important signifier that constructs the Park Street area is the contrast between and the coexistence of the marginal populace of the locality and the affluent classes that gather in the area on a daily basis. In Chaudhuri's narrative this marginal population comprises of migrants from Bihar, the beggars and the pimps who operate in the area. Theirs is a struggle for subsistence and Chaudhuri foregrounds several such individuals as Ramayan Shah, who runs a pavement eatery or Baby Mishra, a beggar from Howrah. The enumeration and detailed highlighting alongside the prominent eateries and shopping establishments of Park Street construct for the readers an affluent middle-class counterpoint to the marginality of the migrants from Bihar and Howrah.

Highlighting of the old reputed eateries (along with their exotic menu) and other similar shopping establishments that line Park Street such as Flurys, Mocambo or the Oxford Bookstore 
also contribute to the construction of Calcutta in Chaudhuri's narrative. One of the best illustrative examples of this method of foregrounding is Chaudhuri's description of the menu of Flurys that he witnessed there as a child:

...where every item on the menu - baked beans on toast, sausage roll, scrambled eggs, pineapple pudding cake, buttered toast - had an idiosyncratic pedigree. That day was the first time I had a chicken croissant - croissant-shaped bread sliced through the middle, buttered, patted with mustard, and filled with shreds of roast chicken. (Chaudhuri, 2016, ch.2).

Bishwanath Ghosh also highlights Park Street in his representation of Calcutta as he constructs the 'gaze' of his readers towards the city. For Ghosh, Park Street is his "second home" (Ghosh, 2014, p. 35) and it is presented as the veritable link between Calcutta's colonial past and its contemporaneity: "Park Street is an event: an elegant dance of the colonial times in the courtyard of contemporary. The show begins at seven-thirty in the morning when Flurys opens. It serves, among other things, English breakfast and therefore remains a living link to the British days." (Ghosh, 2014, p. 36). After the show begins at Flurys the rest of the action unfolds as the other shops and eateries begin to open. Ghosh operates as a tour guide as he points towards the noon-time scene in Park Street when it's ready to lunch as well as the late night scene with smartly dressed young women coming out from Park Hotel and hailing taxis to go home.

Just as Chaudhuri, Bishwanath Ghosh also highlights the food culture of Park Street as he constructs the 'gaze' of his readers towards Calcutta: "Park Street's energy comes from food. Every eatery here is legendary, and finding a table in the most popular ones is always a challenge." (Ghosh, 2014, p. 36) His mention how the queue one has to make outside the famous restaurants such as Mocambo acts as a signifier for this fooding culture. Ghosh, in fact, sums up his own association with the city of Calcutta by foregrounding the signboards of shops and establishments in Park Street, constructing in the process the 'gaze' of his readers, as he says:

I will return to Calcutta again, but I am not sure when, so I have come here to take a good look at the signboards that I have come to associate the city with: Oxford Bookstore; Music World; Flurys; Mocambo; Peter Cat; Trincas; Bar-B-Q; Moulin Rouge; Oasis; Magnolia; Olypub; AN John (hairdressers); Barkat Ali \& Sons (the tailors). (Ghosh, 2014, p. 103).

\section{North Calcutta}

In both the narratives of Chaudhuri and Ghosh, the 'gaze' of the readers towards Calcutta is constructed by foregrounding the areas in North Calcutta that form the origins of the present metropolis. In his representation of Calcutta, Bishwanath Ghosh constructs the 'gaze' of his readers towards the city by a dual strategy: first, in the manner of a tour guide, he narrates the history of the establishment of Calcutta by diffusing certain popular myths about Calcutta (such as, it was not Charnock but later officials of the East India Company like Goldsborough and Charles Eyre who practically laid the foundations of the city). Ghosh then directs his readers' gaze to the area and extent of the early Calcutta comprising "Sutanuti to the north, Gobindapur to the south, and Kalikata between them" (Ghosh, 2014, p. 41) and informs that Calcutta got its name from Kalikata, because the then administrative centre of the Company, Fort William was located in Kalikata. 
The second strategy that Ghosh adopts is by arranging a virtual tour to these old sites in contemporary Calcutta. The tour starts from Sobhabazar in north Calcutta and covers "the entire length of what is geographically north Calcutta or old Calcutta" (Ghosh, 2014, p.105). Running along the Hooghly River through Ahiritola and Nimtala crematorium it terminates at Dalhousie Square, a sort of retro-journey "from the village of Sutanuti to the village of Kalikata." (Ghosh, 2014, p.109) Ghosh completes his presentation of old Calcutta (comprised of Sutanuti, Kalikata and Gobindapur) later on in the narrative as he highlights the history of the establishment of the current Fort William in the then Gobindapur village by Robert Clive. The readers are informed that the establishment of the Fort changed the topography of the original Calcutta forever: "The end result was that Gobindapur vanished from the face of Calcutta and the jungles around it became the Maidan." (Ghosh, 2014, p.304)

The same process of 'gaze' construction is found as Ghosh highlights the Chitpur Road (now renamed as Rabindra Sarani), one that predates the origin of the city of Calcutta itself. The road that stretched eight miles connected the Chitteswari temple in the village of Chitpur located north of Sutanuti to the famous Kali temple at Kalighat in the south. This road ran along the banks of the river Hooghly and as the villages of Sutanuti, Kalikata and Gobindapur merged to form the city of Calcutta, it became one of the major arteries of the city. Stretches of this old road is now known by various names such as Russa Road, Chowringhee Road, Bentinck Street and Chitpur Road.

Not as detailed as Ghosh, but Chaudhuri's Calcutta also highlights the area of North Calcutta as it constructs the 'gaze' of the readers. As for example, Chaudhuri constructs the Shobhabazar area in north Calcutta as "being home to the obscure mansions of erstwhile rajas and landlords" (Chaudhuri, 2016, ch.9) and which boasts of famous landmark buildings such as the Tagores' house in Jorasanko, the Mallickbari or the Marble Palace and the Mahajati Sadan, the playhouse. The area of North Calcutta for Chaudhuri "is not just a geographical location; it is, in fact, the other Calcutta." (Chaudhuri, 2016, ch.9). Most importantly, North Calcutta is the remnant of the old or the 'black' town which provided "the environs in which all the cultural innovations of the Bengal Renaissance took place." (Chaudhuri, 2016, ch.9). This linkage of North Calcutta not only to the origins of the city (as highlighted by Bishwanath Ghosh) but also to the cultural evolution of Calcutta (as foregrounded by Amit Chaudhuri) makes North Calcutta one of the most potent signifiers of the city of Calcutta by which the 'gaze' of the readers is constructed.

\section{Festivals}

\section{Christmas, New Year's Eve, New Year Day}

The next important aspect that Amit Chaudhuri and Bishwanath Ghosh highlight as they construct the 'gaze' of their readers are the major festivals that the city celebrates-Christmas (along with New Year's Eve and the New Year Day) and Durga Puja.

Amit Chaudhuri constructs Christmas and New Year celebrations in Calcutta as it is celebrated in the Park street area, which traditionally has been the domain of the Christian population in the city. What is of special interest in Chaudhuri's narrative is that he foregrounds the responses of his friend from London who witnesses Christmas celebrations in Calcutta for the first time. For him the Christmas of Calcutta has no signs of the crucifix anywhere; there is a glaring lack of the "awful mournfulness of Christianity" (Chaudhuri, 2016, ch. 2) and Christmas here is all about Santa with few nativity scenes around. Chaudhuri points out that indeed to find a 
representation of nativity one needed to go to a church because in Calcutta Christmas, the miraculous birth of Jesus Christ remains more or less unpronounced. Rather, the predominant atmosphere in Calcutta during Christmas "has never been one of solitary stocktaking or of the notion of the return of God to earth, but of make-believe." (Chaudhuri, 2016, ch. 2). His construction of Christmas celebrations in Calcutta, in a manner, becomes synonymous with the craze for Christmas trees that dot the middle-class living rooms, the showrooms, the shops and the cafes or the giant simulacra of Santa Claus stationed in front of shopping malls and the restaurants. Chaudhuri relates all this to the emergence of a "cheery provincialism" (Chaudhuri, 2016, ch. 2) of the new pleasure-loving middle-class in the city who is more inclined to spend the Christmas afternoon with special aimless anticipation: "And in which part of the world could you have such a Christmas afternoon, with its special aimless anticipation - except in Calcutta, and here?" (Chaudhuri, 2016, ch. 2). The high point of this aimless anticipation is in 'eating out', whether it is in posh clubs such as the Bengal Club or upscale restaurants such as Flurys or Mocambo. Chaudhuri details such an elaborate Christmas lunch in Bengal Club that he attends with his family. The lunch itself with its menu and the dress code for its members function as a signifier of Christmas celebration for the readers.

Chaudhuri constructs Christmas celebrations in Calcutta from three perspectives: from his own, as a member of the upper middle-class who has access to elite clubs such as the Bengal Club; from the point-of-view of the pavement dwellers; and thirdly, from the perspective of the common people who come to spend the Christmas afternoon in Park Street. On Christmas day, in front of Ramayan Shah's pavement eatery Chaudhuri "found an odd solitude, a release of purpose. A strange cessation reigned here." (Chaudhuri, 2016, ch. 2). The reason for this inactivity, as he discovers, is that on Christmas Day these pavement dwellers earned less than the normal days. As the representative of the general mass, Chaudhuri foregrounds a lady from Salt Lake who has come to spend the Christmas afternoon in Park Street with her son, her sister and her husband. His highlighting of this lady is significant because she becomes a signifier of "a new kind of provincial who populates the globalised world, who changes with its changes without ever travelling outside of the country, even beyond their city or town." (Chaudhuri, 2016, ch. 2). She is seen sitting on a ledge outside Flurys waiting for her husband to return from the KFC on Middleton Street and Chaudhuri's hint is all too obvious for his readers as he constructs their 'gaze' towards a class that cannot afford an entry into Flurys even, let alone the Bengal Club.

The construction of New Year's Eve in Chaudhuri's Calcutta is also centered in the Park street area. Just as the 'gaze' towards Christmas is constructed from three different perspectives, similar is the construction of New Year's Eve. As for example, in the Bengal Club New Year's Eve garden party, the advent of the coming year is celebrated by playing classic English songs such as 'Scarborough Fair' and 'Blowin' in the Wind'. The perspective of the common mass who has gathered at Park Street for the occasion is different. Chaudhuri highlights the activities of the mass in graphic detail:

Young men in mock-leather jackets swarm the pavements; the street pulsates with excitement as the year dies. Park Street isn't their natural terrain; out of a suppressed sense of exclusion, maybe, and from genuine excitement, they walk about in proprietary groups in front of the famous restaurants of the middle class - Bar-b-que; Moulin Rouge; Peter Cat. (Chaudhuri, 2016, ch. 2).

New Year's Eve for the pavement dwellers is also constructed in similar detail with their unchanged daily routine of ironing clothes for richer patrons or preparing cheap snacks for the poorer revelers. 
In Bishwanath Ghosh's representation of Calcutta also Christmas celebration in the Park Street area is highlighted. He summarizes the relationship of the Calcuttans with Christmas rather brusquely: "On this day, all Calcuttans like to have fruit cake. The adventurous ones venture to Park Street in the evening, and those who have the money and luck find a table to dine in one of its restaurants." (Ghosh, 2014, p.259). Unlike Chaudhuri who constructs the Christmas festivities in Park Street from an intimate personal perspective, Ghosh is a distant observer. This is highlighted, as for example, in his detailed description of the preparation of alu-kabli by a roadside vendor outside Vardaan Market on Camac Street. For Ghosh, savouring alu-kabli outside Vardaan Market on Christmas Day is equally pleasurable as 'eating out' in one of the Park Street restaurants.

New Year's Eve in Bishwanath Ghosh's Longing Belonging is constructed by highlighting the celebrations in "one of the new middle-class-friendly clubs that are a little less fussy about the dos and don'ts." (Ghosh, 2014, p.295) — the Princeton Club on Prince Anwar Shah Road in South Calcutta. Ghosh differentiates this club from the elite clubs of Calcutta with their elaborate etiquette "where aristocratic Bengalis still ape their erstwhile British masters" (Ghosh, 2014, p.295). Bishwanath Ghosh constructs the New Year Day in his representation of Calcutta by highlighting the New Year's Day races that the Royal Calcutta Turf Club organizes every year. Ghosh, as he constructs the 'gaze' of his readers, draws up a catalogue of the types of people that he finds attending the races: the 'British Bengali, the 'Indian' Bengali and the rich non-Bengalis. There is also a fourth category, as Ghosh points out: commoners who have come here with the sole aim of making quick money. The Royal Calcutta Turf Club, in Longing Belonging, virtually becomes a living museum of the class and community profile of Calcutta for the readers to 'gaze' at.

\section{Durga Puja}

In both Calcutta and Longing Belonging, Durga Puja finds a prominent place in the representation of the city and the 'gaze' of the readers is constructed by highlighting the various facets of this biggest festival of the Bengalis. Bishwanath Ghosh is more elaborate in his narration as he constructs Durga Puja from varied perspectives for his readers: first, the origin of barowari or community Puja is Bengal; second, the activities in Kumartuli where the Durga idols are made; and third, Durga Puja as it is celebrated in contemporary Calcutta. Ghosh highlights the origin and growth of Durga Puja in its present form as he narrates how the first barowari Puja was organised in 1790 in Guptipara, $75 \mathrm{~km}$ north of Calcutta, by twelve excommunicated young men; how during the nationalist movement the Durga Puja "began to spread to nooks and corners of Bengal, certainly of Calcutta, as an assertion of native identity." (Ghosh, 2014, 196) and how in the present times celebration of the Puja in every neighbourhood has become a means of asserting group/community existence in a megacity. Also highlighted in Longing Belonging is the lore associated with the Pujas organised by the babus of Calcutta, the most prominent example being the Durga Puja organised by Raja Nabakrishna Deb in the autumn of 1757 where Robert Clive was the chief guest.

Bishwanath Ghosh also constructs Durga Puja in Calcutta by highlighting the activities in Kumartuli in north Calcutta where the Durga idols are made. As part of his strategy, Ghosh foregrounds the character of an idol maker Debabrata Pal who is not only a veteran artisan but also owns a workshop in Kumartuli. Ghosh goes on to present the yearly calendar of the Kumartuli artisans from these words of Debabrata Pal: "Durga Puja is followed by Lakshmi Puja; 
Lakshmi Puja is followed by Kali Puja; Kali Puja is followed by Jagadhatri Puja; a couple of months after Jagadhatri Puja comes Saraswati Puja, which is celebrated in February. By March or April we are back working on Durga idols." (Ghosh, 2014, p.208).

The third aspect of this construction of Durga Puja in Ghosh's representation of Calcutta is how the festival is celebrated in contemporary Calcutta. This is done by foregrounding both the religious as well as the festive rituals associated with the Puja that very often function as the signifiers of the festival itself. The first example that Ghosh provides is the listening to the broadcast of the Mahishasura Mardini hymn on the day of the Mahalaya. Ghosh uses series of signifiers to construct the aura of present-day Durga Puja: "shopping malls resemble gardens in full bloom" (Ghosh, 2014, p.195); the excitement of the radio jockeys; Puja-related hoardings; Puja pandals constructed even in the narrowest of thoroughfares; the network of loud speakers tied to electric poles and bamboo posts constantly playing songs. As part of the 'gaze' construction process of the readers, the religious rituals associated with the Puja such as bhog ("food for the goddess" (Ghosh, 2014, p.203)) and pushpanjali ("ritual offering of flower to the goddess" (Ghosh, 2014, p.372)) are also highlighted. Also mentioned is the practice of pandal-hopping on the Durga Puja days (especially during nighttime) as Ghosh foregrounds his own experience of visiting some of the renowned pandals in North and South Calcutta such as Park Circus, Mohammad Ali Park or Maddox Square.

Amit Chaudhuri's construction of Durga Puja as he represents Calcutta is in many ways similar to that of Ghosh but it also differs in several aspects. Like Ghosh, Chaudhuri also points out that before the Puja celebrations percolated down to the community level, it was the prerogative of a handful of powerful families. But Chaudhuri's construction of Durga Puja contains several additional elements, as for example, he points out that the introduction of community Pujas robbed the festival of its religious overtones and it became an occasion of secular merrymaking. Chaudhuri's narrative also foregrounds the fact by the 1980s the Pujas, almost imperceptibly, became "the world's most extraordinary festival, holding absolute, even tyrannical, sway over the city for as long as they lasted." (Chaudhuri, 2016, ch. 8) and by the early 1990s, the resident middle-classes of the city started leaving their homes during the duration of the Pujas to escape the Puja noise and crowds. Chaudhuri, as he constructs the 'gaze' of his readers, specially highlights the pandals and the lighting that are part and parcel of contemporary Puja celebrations in Calcutta These pandals and lighting, that started flourishing from the 1980s onwards, are often theme-based and form the main source of attraction for the pandal-hopping crowd. The 'gaze' of the readers is further constructed by foregrounding the myths associated with Durga Puja: the myth of Durga, the mother, who comes down to slay the devil and the myth of Durga, the daughter, who must go back to her husband after the festival is over. Chaudhuri points towards the uniqueness of this myth that has transformation as its basis:

We've become her father; and, like every father, we know it's futile to want to keep back a married daughter - she's not ours to keep. In the Pujas' ten days, we've somehow aged and spanned a lifetime, from being child to parent, as characters often do in the course of a novel. (Chaudhuri, 2016, ch. 8).

\section{Conclusion}

There is an undeniable relationship between representation and 'construction' in narratives of any form because representation involves selecting, foregrounding and highlighting of events and issues to make it comprehensive to its recipients. Herein lays the 'constructive' aspect of 
narratives in general and travel narratives in particular. But, in the case of travel narratives such exercises of selection and highlighting perform an almost imperceptible secondary function-that of construction of the 'gaze' of the readers towards a particular destination or object. The rationale behind such selection of incidents/events is determined by the discursive structures within which the writers of travel narratives operate. Semiotics comes into play at this stage as the signifiers that are foregrounded in the construction of 'gaze' are dependent on such discursive structures. Such discursive structures might vary from writer to writer as the same destination/event might be 'constructed' entirely from the writer's ideological bias or as in the case of commercial tour guides, from the requirements of the marketing agencies. This inevitably leads to variations in representation of any destination/event/personality that the travel writer might choose to project. In this paper there has been an effort to 'structure' such variations in the representation of Calcutta by Amit Chaudhuri and Bishwanath Ghosh under certain common heads, such as 'Spaces' and 'Festivals', as they construct the 'gaze' of their readers towards the city of Calcutta.

\section{References}

Bhattacharji, S. (Ed.). (2008). Travel Writing in India. New Delhi: Sahitya Akademi.

Chandler, D. (2007). Semiotics: The Basics. Routledge.

Chaudhuri, A. (2016).Calcutta: Two Years in the City. Kindle ed., Penguin Books.

Cobley, P. (2001). Narrative. Routledge.

Ghosh, B. (2014). Longing Belonging: An Outsider at Home in Calcutta. Kindle ed., Tranquebar Press.

Hall, S. (Ed). (1997). Representation: Cultural Representations and Signifying Practices. Sage Publications Ltd.

Jorgensen, M. and Phillips, L. J. (2002). Discourse Analysis as Theory and Method. Sage Publications Ltd.

Mills, S. (2004). Discourse. Routledge.

Moraes, D. (Ed). (2004). The Penguin Book of Indian Journeys. Penguin.

Urry J. \& J. Larsen (2011). The Tourist Gaze 3.o. Sage Publications Ltd. 